\title{
Parâmetros bromatológicos e fermentativos das silagens de milho e girassol
}

\author{
Bromatological and fermentative parameters of corn and sunflower silages
}

\author{
Rosana Aparecida Possenti ${ }^{1}$ Evaldo Ferrari Junior ${ }^{1}$ Mauro Sartori Bueno ${ }^{1}$ \\ Diorande Bianchini ${ }^{2}$ Frederico Fontoura Leinz ${ }^{2}$ \\ Carlos Frederico Rodrigues ${ }^{2}$
}

\section{RESUMO}

\begin{abstract}
Foi desenvolvido no Instituto de Zootecnia, Agência Paulista de Tecnologia dos Agronegócios (APTA), São Paulo um experimento com o objetivo de avaliar quimicamente a qualidade das silagens e a degradação ruminal da matéria seca (MS), fibra detergente neutra (FDN) e proteína bruta (PB) das silagens de milho e girassol. Na avaliação químico-bromatológica das silagens, utilizou-se delineamento estatístico inteiramente ao acaso com nove repetições por tratamento (silagem de milho ou girassol) e, para a degradação in situ, utilizou-se delineamento em parcelas subdivididas, com três repetições. A silagem de girassol apresentou maiores concentrações de proteína bruta (11,6 vs 9,4\%), extrato etéreo (10,1 vs 3,2\%), fibra detergente ácida (42,7 vs 31,9\%)e lignina (9,4 vs 3,7\%), e menores teores de MS (22,0 vs 34,6\%) que a silagem de milho, respectivamente. Apresentou também maiores teores de nitrogênio amoniacal (10,7 vs 5,8 \%) e ácido acético (3,0 vs $0,79 \%)$ e menores concentrações de ácido lático (3,7 vs $11,3 \%)$ que a silagem de milho. As taxas de degradação efetiva da MS, FDN e PB da silagem de girassol foram menores do que as da silagem de milho. A silagem de milho apresentou características mais favoráveis ao processo de ensilagem.
\end{abstract}

Palavras-chave: ácidos orgânicos, degradação efetiva, degradação potencial, fibra detergente ácido e neutro, lignina.

\section{ABSTRACT}

At the Instituto de Zootecnia, APTA, São Paulo StateBrazil, it was carried out an experiment to evaluated the chemical quality and ruminal degradation for dry matter (DM), neutral detergent fiber (NDF) and protein (CP) of sunflower and corn silages. For chemical evaluation of the silages, a total randomized design with nine replicates was used. For in situ degradability was used a split-plot design with three replicates, in which the plots were the times of incubation and the subplot the silage. Sunflower silage showed higher concentration of crude protein (11.6 vs 9.4\%), ether extract (10.1 vs 3.2\%), acid detergent fiber (42.7 vs 31.9\%) and lignin (9.4 vs 3.7\%), and lower concentration of dry matter than corn silage (22.0 vs 34.6\%), respectively; and also higher concentration of ammonia nitrogen (10.7 vs $5.8 \%$ ) and acetic acid (3.0 vs $0.79 \%)$ and lower concentration of lactic acid (3.7 vs 11.3\%) than corn silage. The effective degradation rates of DM, NDF and CP were lower in the sunflower silage. Corn silage showed more favorable characteristics for ensiling process.

Key words: acid and neutral detergent fiber, effective degradability, lignin, organic acid, potential degradability.

\section{INTRODUÇÃO}

A utilização de silagens tem sido uma eficiente solução para os períodos de baixa produção de forragens, proporcionando volumoso de boa qualidade e largamente utilizado na alimentação de ruminantes. O milho é uma das melhores plantas para ensilar, pois apresenta boa produção de MS por hectare e elevado valor nutritivo. No momento propício ao corte, possui adequado teor de MS e carboidratos solúveis, o que lhe confere ótimas condições para sua conservação na forma de silagem (ALMEIDA, 2000), produzindo alimento de ótima qualidade e de boa aceitação pelos animais.

\footnotetext{
${ }^{1}$ Secretaria da Agricultura e Abastecimento do Estado de São Paulo, Agência Paulista de Tecnologia dos Agronegócios, Instituto de Zootecnia, Centro de Pesquisa e Desenvolvimento em Nutrição Animal e Pastagens, CP 60, 13.460-000, Nova Odessa, SP, Brasil. Email:possenti@iz.sp.gov.br; ferrari@iz.sp.gov.br; bueno@iz.sp.gov.br

${ }^{2}$ Secretaria da Agricultura e Abastecimento do Estado de São Paulo, Agência Paulista de Tecnologia dos Agronegócios, Unidade de Pesquisa e Desenvolvimento de Itapetininga, CP 169, 18200-000, Itapetininga, SP, Brasil. Email: upditaptininga@aptaregional.sp.gov.br
} 
O girassol apresenta-se como alternativa para produção de silagem, pois seu cultivo tem aumentado consideravelmente em nosso meio, face à grande demanda existente no mercado pelo seu óleo (LIMA et al., 1999), podendo substituir o milho em regiões onde condições climáticas, ou época do ano, sejam limitantes a esta cultura. A silagem de girassol apresenta composição bromatológica distinta à silagem de milho ou sorgo, com maiores teores de proteína bruta e extrato etéreo (HENRIQUE et al., 1998). A composição de sua parede celular mostra maiores variações, de acordo com a literatura corrente (ALMEIDA et al., 1995; HENRIQUE et al., 1998; LIMA et al., 1999).

A avaliação in situ, através da utilização de saquinhos de náilon, possibilita estimar a degradabilidade potencial da forragem (ØRSKOV \& McDONALD, 1979) e apresenta elevada correlação com os resultados obtidos em experimentos in vivo. Desta maneira permite conhecer a cinética de digestão ruminal dos volumosos e seu potencial como alimento para animais ruminantes.

O objetivo deste estudo foi avaliar a composição químico-bromatológica das silagens de milho ou girassol e seus valores de degradação ruminal.

\section{MATERIAL E MÉTODOS}

O plantio e confecção das silagens foram realizados nas dependências da Unidade de Pesquisa e Desenvolvimento de Itapetininga - SP, e as análises químicas e de degradabilidade in situ no Instituto de Zootecnia, Nova Odessa - SP, ambos pertencentes à Secretaria da Agricultura e Abastecimento, Agência Paulista de Tecnologia dos Agronegócios (APTA).

Foram utilizadas sementes de milho cultivar AL-34, fornecidas pela Coordenadoria de Assistência Técnica Integral (CATI) da Secretaria da Agricultura e Abastecimento - SP e para o girassol sementes do cultivar RUMBOSOL-91, fornecidas pela empresa Sinuelo \& Genética Tecnologia Agropecuária - PR. Uma área de 1 ha foi utilizada para cada cultura. Os plantios foram efetuados em linhas distanciadas de $0,80 \mathrm{~m}$, com 5 e 4 plantas por metro linear, respectivamente, para milho e girassol. As duas culturas receberam adubação de $500 \mathrm{~kg} \mathrm{ha}^{-1}$ da formula 04-14-08 na semeadura e cobertura de $250 \mathrm{~kg} \mathrm{ha}^{-1}$ de sulfato de amônia após 45 dias; a erradicação das pragas invasoras foi feita mecanicamente e não foi aplicado inseticida ou qualquer outro defensivo agrícola nas áreas cultivadas. O ponto de colheita para ensilagem do milho foi quando os seus grãos estavam no estádio farináceo e para o girassol quando os capítulos encontravam-se voltados para baixo com a parte dorsal na coloração amarelo queimado. O corte foi feito com colhedeira de forragens acoplada ao trator e o material colhido foi compactado em tambores plásticos, com capacidade de 150 litros. Permaneceu nestes recipientes por um período de 60 dias, e foi posteriormente aberto e coletadas amostras para determinações químicas e ensaio de degradabilidade in situ. O delineamento estatístico utilizado foi inteiramente ao acaso, com nove repetições (tambores plásticos das silagens de milho e girassol).

Para avaliação da composição químicobromatológica das silagens, foram efetuadas as determinações de matéria seca (MS), proteína bruta (PB), fibra bruta (FB), extrato etéreo (EE), matéria mineral (MM) e estimado o teor de extrativos não nitrogenados (ENN) segundo AOAC (1975). Os teores de fibra detergente neutro (FDN), fibra detergente ácido (FDA), hemicelulose, celulose e lignina foram efetuados conforme GOERING \& VAN SOEST (1970) e o pH, ácidos orgânicos e nitrogênio amoniacal como \% do nitrogênio total ( ${\mathrm{N}-\mathrm{NH}_{3} /}^{\prime}$ \%NT) de acordo com BOIN (1975).

No experimento de degradação in situ, foram utilizados três bovinos machos, da raça Holandês vermelho e branco, castrados, com peso médio de $600 \mathrm{~kg}$, portadores de cânulas ruminais. Os animais receberam uma dieta à base de silagem de milho e silagem de girassol, na proporção de 1:1, farelo de soja e sal mineral. O experimento de degradação in situ foi em blocos ao acaso, com parcelas subdivididas, com três repetições, onde as parcelas foram os tempos de incubação ( $3,6,12,24$, 48 e 72 horas), e as subparcelas as silagens de milho ou girassol. A degradação in situ foi estimada através da técnica descrita por MEHREZ \& ØRSKOV (1977). Os tempos de incubação dos sacos de náilon foram: zero, 3, 6, 12, 24, 48 e 72 horas. Nas amostras incubadas, foram determinados os teores de MS, PB, FDN, segundo AOAC (1975) e GOERING \& VAN SOEST (1970), respectivamente. Os dados de degradação in situ da MS, PB e FDN foram ajustados no modelo matemático proposto por ØRSKOV \& McDONALD (1979): $p=a+b\left(1-e^{-c t}\right)$. As equações de degradação in situ e dos parâmetros (a, b, c) foram estimadas pelo método interativo provido pelo SAS (1993). Para as análises estatísticas adotou-se um nível de 5\% de probabilidade de erro.

\section{RESULTADOS E DISCUSSÃO}

Os teores médios de matéria seca da silagem de milho (Tabela 1) foram superiores aos da silagem de girassol e estão dentro dos valores considerados adequados a um bom padrão fermentativo (FERREIRA, 
Tabela 1 - Teores médios de matéria seca (MS), matéria orgânica (MO), proteína bruta (PB), extrato etéreo (EE), matéria mineral (MM), extrativos não nitrogenados (ENN), fibra detergente neutro (FDN), fibra detergente ácido (FDA), hemicelulose (HEM), celulose (CEL) e lignina (LIG) das silagens.

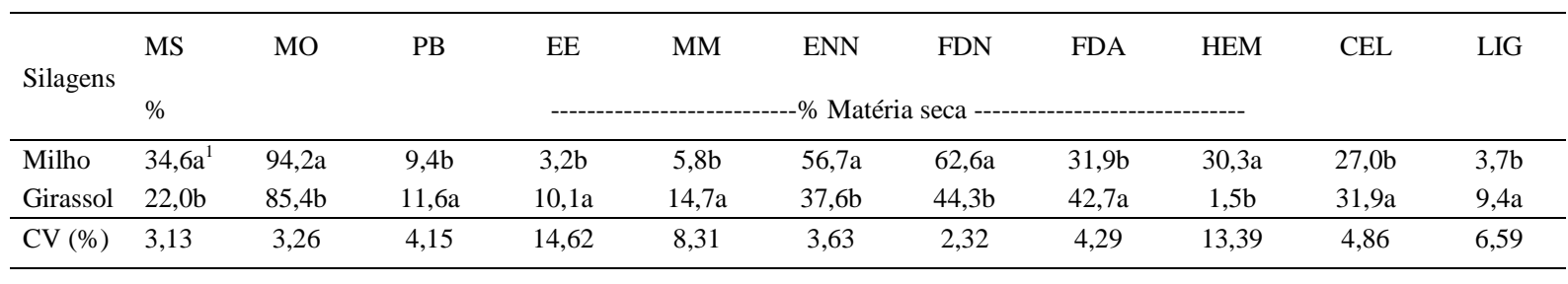

${ }^{1}$ Médias seguidas por letras distintas na coluna, diferem entre si pelo teste $\mathrm{F}$ em nível de 5\% de probabilidade de erro.

2001). Os teores médios de matéria seca da silagem de girassol foram inferiores aos citados por HENRIQUE et al. (1998), que encontraram valores ao redor de $25 \%$ para a de girassol e $30-35 \%$ na silagem de milho. Considerando que o conteúdo de água na forragem deve situar-se entre 65 a $70 \%$, para uma eficiente armazenagem do material ensilado, neste estudo, ficou evidente que o milho portou-se como planta mais adequada ao processo de conservação na forma de silagem. Outro aspecto relevante é que o milho melhor evidencia suas alterações morfológicas durante seu ciclo, que permitem verificar de forma simples o momento mais apropriado para o corte. A silagem de girassol apresentou teores mais elevados de proteína bruta, o que também foi verificado por HENRIQUE et al. (1998), LIMA et al. (1999) e GONÇALVES et al. (2000). Este pode ser um ponto positivo para essas silagens, porque podem promover maior economia na utilização de fontes protéicas na formulação de dietas para ruminantes.

Os teores de extrato etéreo (Tabela 1 ) foram mais elevados na silagem de girassol, devido ao fato de ser um vegetal que armazena sua energia no grão na forma de óleo. Os valores de extrativos não nitrogenados foram superiores para a silagem de milho, o que para o milho denota seu elevado teor de amido. A composição da parede celular das silagens foi muito distinta. A silagem de milho apresentou maiores teores de fibra detergente neutra e hemicelulose e menores de fibra detergente ácido, celulose e lignina do que a silagem de girassol. Os valores de fibra detergente neutro para a silagem de milho estão dentro da amplitude de variação de 49,1 a 68,4\%, citados por LIMA et al. (1999). A parede celular da silagem de girassol parece ser formada quase que unicamente de lignocelulose, com teores muito baixos de hemicelulose. Valores baixos desta fração, entre 3,4 e 5,0\%, foram obtidos por HENRIQUE et al. (1998), embora outros autores (ALMEIDA et al., 1995) tenham encontrado valores mais elevados da hemicelulose (30\%).
Diferenças entre cultivares de girassol parecem existir, uma vez que LIMA et al. (1999) e GONÇALVES et al. (2000) observaram valores entre 3,4 a $13,5 \%$ e 8,1 a $12,7 \%$ de hemicelulose, respectivamente. As concentrações de lignina na silagem de girassol foram maiores que as da silagem de milho. A silagem de girassol apresentou valores 2,5 vezes maiores que a do milho, o que pode ser considerado como fator negativo do ponto de vista nutricional, concordando com as citações de LIMA et al. (1999) e PEREIRA et al. (2002).

$\mathrm{O} \mathrm{pH}$ da silagem de milho mostrou-se adequado e foi mais baixo que o da silagem de girassol (Tabela 2). Esses valores, provavelmente se justificam devido aos altos valores de PB do girassol que, durante a decomposição protéica da massa ensilada, podem produzir compostos nitrogenados que neutralizam o ácido lático, aumentando o $\mathrm{pH}$ (BREIREM \& ULVESLI, 1960). As proporções de nitrogênio na forma de $\mathrm{N}-\mathrm{NH}_{3}$ foram mais elevadas para a silagem de girassol. Apesar de seu alto teor de proteína bruta e excesso de umidade no material ensilado, a silagem de girassol apresentou valores de $\mathrm{N}-\mathrm{NH}_{3}$ de 10,77\% em relação ao nitrogênio total, valores estes considerados como aceitáveis para silagens de boa qualidade, de acordo com LAVEZZO \& ANDRADE (1994), que citam como valores normais a variação de 0 a $12,5 \%$ N-NH 3 /NT.

Tabela 2 - Valores médios de $\mathrm{pH}(\mathrm{pH})$, nitrogênio amoniacal (N$\mathrm{NH}_{3} / \% \mathrm{NT}$ ), ácido lático (LAT\%) e ácido acético (ACE\%), das silagens.

\begin{tabular}{|c|c|c|c|c|}
\hline \multirow{2}{*}{ Silagens } & \multirow{2}{*}{$\mathrm{pH}$} & \multirow{2}{*}{$\mathrm{N}-\mathrm{NH}_{3} / \% \mathrm{NT}$} & LAT & $\mathrm{ACE}$ \\
\hline & & & \multicolumn{2}{|c|}{----------\%MS------- } \\
\hline Milho & $4,08 b^{1}$ & $5,87 b$ & $11,32 \mathrm{a}$ & $0,79 b$ \\
\hline Girassol & $5,14 a$ & $10,77^{\mathrm{a}}$ & $3,72 b$ & $3,00 \mathrm{a}$ \\
\hline CV (\%) & 2,45 & 8,94 & 16,99 & 12,29 \\
\hline
\end{tabular}

${ }^{1}$ Médias seguidas por letras distintas na coluna, diferem entre si pelo teste $\mathrm{F}$ em nível de 5\% de probabilidade de erro. 
As concentrações médias de ácido butírico na matéria seca $(0,03 \%)$, podem ser consideradas como baixas, na silagem de girassol, não caracterizando intensa degradação de aminoácidos. Na silagem de milho, as concentrações médias de ácido butírico observadas foram de 0,01\% na matéria seca. As concentrações de ácido lático foram maiores e as de ácido acético menores na silagem de milho. As concentrações de ácido lático na silagem de milho estão acima dos valores de 4 a 6\% e as de ácido acético abaixo de 2\% na MS, valores estes apontados por VILELA (1998) para silagens de milho bem preparadas. Entretanto, a silagem de girassol não apresentou adequada concentração de ácido lático (3,7\%), o que provavelmente contribuiu para maiores valores de $\mathrm{pH}$.

A neutralização do ácido lático pode ocorrer, devido a dissociação de $\mathrm{H}^{+}$, entretanto, quando há muito nitrogênio livre ocorre a "captura” destes íons, formando $\mathrm{NH}_{4}^{+}$que, dependendo da quantidade formada, promove um aumento de $\mathrm{pH}$ do meio. Este processo é observado com freqüência em silagens de leguminosas ou de materiais tratados com uréia, (Mc DONALD, 1981). Um pH estável não é obtido nas silagens, também devido à deficiência de carboidratos solúveis ou devido à excessiva umidade do material, (LAVEZZO \& ANDRADE, 1994). No presente estudo, pode-se inferir que estes fatores foram preponderantes nos valores de $\mathrm{pH}$, observados para a silagem de girassol. PEREIRA et al (2002) sugerem que, para silagens de girassol, os silos experimentais devem ser dotados de compartimentos de escape de efluentes, para que se aproximem mais da realidade de silos convencionais de fazenda que possibilitam a saída de efluentes através de drenos ou pela absorção do solo.
Os autores alertam que diferentes tipos de silos (experimentais) podem afetar a qualidade e valor nutritivo das silagens de girassol com baixos conteúdos de matéria seca.

A silagem de girassol apresentou valores da fração prontamente solúvel no rúmen “a”, para matéria seca, fibra detergente neutro e proteína bruta (Tabela 3), inferiores à silagem de milho. A fração potencialmente degradável no rúmen (constante b) da matéria seca e fibra detergente neutro da silagem de girassol, também foram menores a de milho; entretanto, os valores médios de "b" para a proteína bruta foram maiores na silagem de girassol. A taxa de degradação da fração potencialmente degradável “c” para a matéria seca não diferiu entre silagens, contudo, na silagem de girassol os valores foram mais elevados para a fibra detergente neutro e menores para a proteína bruta.

Os valores das degradações efetivas para taxas de passagem de 2 , 4 , e $6 \% \mathrm{~h}^{-1}$ foram menores para a silagem de girassol, em todas as frações nutricionais estudadas. Os valores médios da fração “a” para matéria seca da silagem de girassol obtidos por BERGAMASCHINE et al. (1999), foram ligeiramente superiores aos observados neste estudo, e correspondem, em média, a 50\% dos valores obtidos por MIR et al. (1992) e RAMOS et al. (2001). Todavia os valores médios da fração potencialmente degradável "b”, para a proteína bruta da silagem de girassol foram superiores aos observados pelos autores citados. Os valores de "a”, "b” e “c” da matéria seca da silagem de milho encontrados neste trabalho foram semelhantes aos descritos por MIR et al. (1992).

A cinética da degradação da matéria seca e fibra detergente neutro foram diferentes entre as

Tabela 3 - Parâmetros da degradação ruminal da matéria seca (MS), fibra detergente neutro (FDN) e proteína bruta (PB) das silagens de milho e girassol

\begin{tabular}{|c|c|c|c|c|c|c|c|}
\hline Silagens & $\begin{array}{l}\mathrm{a}^{*} \\
(\%)\end{array}$ & $\begin{array}{l}b^{*} \\
(\%)\end{array}$ & $\begin{array}{c}\mathrm{c}^{*} \\
(\% / \mathrm{h})\end{array}$ & $\begin{array}{l}\mathrm{Dp}^{*} \\
(\%)\end{array}$ & $\begin{array}{c}\mathrm{De}^{* *} \\
(2 \% / \text { hora })\end{array}$ & $\begin{array}{c}\mathrm{De}^{* *} \\
(4 \% / \text { hora })\end{array}$ & $\begin{array}{c}\mathrm{De}^{* *} \\
(6 \% / \text { hora })\end{array}$ \\
\hline \multicolumn{8}{|c|}{ Matéria seca } \\
\hline Milho & $24,89 a^{1}$ & $56,16 a$ & $4,68 a$ & $81,06 a$ & $63,86 a$ & $54,81 a$ & 49,19a \\
\hline Girassol & $14,52 b$ & $45,39 b$ & 5,33a & $59,91 b$ & $47,50 \mathrm{~b}$ & $40,42 b$ & $35,85 b$ \\
\hline \multicolumn{8}{|c|}{ Fibra detergente neutro } \\
\hline Milho & $17,15 a$ & $79,25 a$ & $2,00 \mathrm{~b}$ & $96,39 a$ & 56,59a & 43,43a & $36,86 a$ \\
\hline Girassol & $9,09 b$ & $39,13 b$ & $3,62 a$ & $48,22 b$ & $34,17 b$ & $27,57 b$ & $23,72 b$ \\
\hline \multicolumn{8}{|c|}{ Proteína bruta } \\
\hline Milho & $45,24 a$ & $31,25 b$ & $15,50 \mathrm{a}$ & $76,48 b$ & $72,87 a$ & $70,02 \mathrm{a}$ & $67,70 \mathrm{a}$ \\
\hline Girassol & $25,84 b$ & $57,35 a$ & $7,15 b$ & $83,18 \mathrm{a}$ & $70,21 b$ & $62,10 \mathrm{~b}$ & $56,53 b$ \\
\hline
\end{tabular}

${ }^{1}$ Médias seguidas por letras distintas nas colunas, diferem entre si pelo teste $\mathrm{F}$ em nível de 5\% de probabilidade de erro.

* Constantes do modelo $\mathrm{p}=\mathrm{a}+\mathrm{b}\left(1-\mathrm{e}^{-\mathrm{ct}}\right)$, ØRSKOV \& McDONALD (1979).

**Constantes do modelo $\mathrm{p}=\mathrm{a}+(\mathrm{b}$ x c) $/(\mathrm{c}+\mathrm{k})$, onde $\mathrm{k}=2$, 4 e 6 \%/hora, ØRSKOV (1982). 
silagens, pois a silagem de milho, devido à composição de sua parede celular, menos lignificada e com maiores teores de hemicelulose, mostrou melhor degradação ruminal, enquanto que a de girassol, devido provavelmente, aos elevados teores de fibra lignificada, foi menos susceptível ao ataque dos microorganismos ruminais. Entretanto, a silagem de girassol com seu maior teor protéico aliado à menor solubilidade inicial (fração a) e elevada degradabilidade potencial (fração b) pode ser ressaltada para sua utilização como volumoso de elevado teor protéico para ruminantes.

\section{CONCLUSÕES}

A silagem de girassol apresentou maiores concentrações de extrato etéreo, fibra detergente ácido e lignina, e baixos teores de matéria seca, os quais podem ser considerados como fatores de restrição na alimentação animal, mas elevada degradabilidade ruminal da fração “b”, favorecendo sua utilização como fonte proteica para ruminantes. A qualidade fermentativa da silagem de girassol foi inferior á do milho.

\section{REFERÊNCIAS}

ALMEIDA, J.C.C. Avaliação das características agrônomicas e das silagens de milho e de sorgo cultivados em quatro densidades de semeadura. 2000. 82f. Tese (Doutorado em Zootecnia) - Faculdade de Ciências Agrárias e Veterinárias, UNESP Jaboticabal.

ALMEIDA, M.F. et al. Composição química e consumo voluntário das silagens de sorgo, girassol e milho para ruminantes, em dois estádio de corte. Ciência e Pratica, v.19, n.1, p.315-321, 1995.

ASSOCIATION OF OFFICIAL ANALITICAL CHEMISTS AOAC. Official methods of analysis. 12.ed. Whashington, DC, 1975. 1094p.

BERGAMASCHINE, F. A. et al. Digestibilidade e degradação in situ da silagem de girassol confeccionada com diferentes teores de matéria seca e aditivo bacteriano. In: REUNIÃO ANUAL DA SOCIEDADE BRASILEIRA DE ZOOTECNIA, 36., 1999, Porto Alegre. Anais... Porto Alegre : Sociedade Brasileira de Zootecnia, 1999. CD-ROM.

BOIN, C. Elephant (Napier) grass silage production, effect of addition on chemical composition, nutritive value and animal performances. 1975. 215f. Tese (Doutorado em Nutrição Animal) - Cornell University.

BREIREM, K.; ULVESLI, O. Ensiling methods. Herbage Abstracts, v.30, n.1, p.1-8, 1960.

FERREIRA, J.J. Características qualitativas e produtivas da planta de milho e sorgo. In: CRUZ, J.C., et al. (Eds). Produção e utilização de silagem de milho e sorgo. Sete Lagoas: EMBRAPA, 2001. p.383-404.
GOERING, H.K.; Van SOEST, P.J. Forage fiber analysis (apparatus, reagents, procedures, and some applications). Washington, DC : ARS-USDA, 1970. (Agriculture Handbook, 379).

GONÇALVES, L.C., et al. Produção e utilização de silagens de girassol. In: SIMPÓSIO DE FORRAGICULTURA E PASTAGENS, 1., 2000, Lavras. Anais... Lavras: Universidade Federal de Lavras, 2000. p.203-236.

HENRIQUE, W. et al. Silagem de milho, sorgo, girassol e suas consorciações. II. Composição bromatológica, 1998. In: REUNIÃO ANUAL DA SOCIEDADE BRASILEIRA DE ZOOTECNIA, 1998, Botucatu. Anais... Botucatu : Sociedade Brasileira de Zootecnia, 1998 p.379-381.

LAVEZZO,W.; ANDRADE, J.B. Conservação de forragens: feno e silagem. In: SIMPÓSIO BRASILEIRO DE FORRAGENS E PASTAGENS, 1994, Campinas, SP. Anais... Campinas: Colégio Brasileiro de Nutrição Animal, 1994. p.105-166.

LIMA, M.L.M., et al. Culturas não convencionais - girassol e milheto. In: SIMPÓSIO SOBRE NUTRIÇÃO DE BOVINOS, 7., 1999, Piracicaba. Anais... Piracicaba : Fundação de Estudos Agrários Luiz de Queiroz, 1999. p.167-195.

McDONALD, P. The biochemistry of silage. New York: John Wiley and Sons, 1981. 226p.

MEHREZ A.Z.; ØRSKOV, E.R. A study of the artficial fibre bag technique for determining the digestibility of feeds in rumen. Journal Agricultural Science, v.88, n.3, p.645650, 1977.

MIR, Z. et al. Ruminal degradation characteristics of corn and corn-sunflower intercropped silages prepared at two stages of maturity. Canadian Journal Animal Science, v.92, n.4, p.881-889, 1992.

ØRSKOV, E.R. Protein nutrition in ruminants. London: Academic, 1982. 160p.

ØRSKOV, E.R.; McDONALD, I. The estimation of the protein degradability in the rumen from incubation measurements weighed according to rate of passage. Journal of Agricultural Science, v.92,n.2, p.499-503, 1979.

PEREIRA, G.R. et al. Digestibilidade in vitro da matéria seca, carboidratos solúveis, frações fibrosas e ácidos orgânicos das silagens de três genótipos de girassol obtidas em três tipos de silos de laboratório, 2002. In: REUNIÃO ANUAL DA SOCIEDADE BRASILEIRA DE ZOOTECNIA, 39., 2002, Recife. Anais... Recife : Sociedade Brasileira de Zootecnia, 2002. CD-ROM.

RAMOS, B.M.O. et al. Degradabilidade ruminal in situ de silagem de girassol em dois estádios vegetativos de corte com sem adição de casca de soja, 2001. In: REUNIÃO ANUAL DA SOCIEDADE BRASILEIRA DE ZOOTECNIA, 38., 2001, Piracicaba. Anais... Piracicaba : Sociedade Brasileira de Zootecnia, 2001. CD-ROM.

SAS Institute. SAS/STAT user's guide: statistic. 4.ed. Version 6, Cary:1993. V.2. 943p.

VILELA, D. A ditivos para silagem de plantas de clima tropical, 1998. In: REUNIÃO ANUAL DA SOCIEDADE BRASILEIRA DE ZOOTECNIA, 35., 1998, Botucatu. Anais... Botucatu: Sociedade Brasileira de Zootecnia, 1998. p.73-108. 